\title{
Prevalence of nontraumatic foot pain among urban young working women and its contributing factors
}

\author{
Yeok Pin Chua $^{1}$, MBBS, MS, Wei Jing Tan ${ }^{2}$, MBBS, MS, Tunku Sara Tunku Ahmad Yahya ${ }^{1}$, MBBS, FRCSG, \\ Aik $\underline{\text { SaW }}^{1}$, MBBS, FRCSE
}

\begin{abstract}
INTRODUCTION Foot pain is a common problem, especially in women, and studies have shown that it is related to footwear. This study was conducted to establish the prevalence of nontraumatic foot pain and its contributing factors in young working Malaysian women in an urban setting.

METHODS The survey was conducted on a group of working women (age range 21-40 years) selected using convenience sampling. Data on foot problems was collected through an investigator-directed questionnaire and during clinical inspection of the foot.

RESULTS A total of 400 women, with a mean age of 29.4 years, were recruited. Half $(n=200)$ of the women had experienced recurrent nontraumatic foot pain in the past one year. Subjective assessments of foot pain using the Numeric Intensity Scale gave an average score of $4.89 \pm 1.78$ (range 2-10), with most episodes occurring at the heel. There was no statistically significant association between foot pain and age, ethnicity or body mass index. However, there was a higher incidence of foot pain in women wearing high-heeled footwear than those wearing non-high-heeled footwear ( $p=0.027$, odds ratio 1.591 ).

CONCLUSION Nontraumatic foot pain is common among young working women in our society. More than half $(68.4 \%)$ of the women with foot pain in our study attributed the pain to footwear. Wearing high-heeled shoes to work was a significant contributing factor. Increased public awareness on the importance of proper footwear may help to reduce the prevalence of nontraumatic foot pain in working women.
\end{abstract}

Keywords: high heels, nontraumatic foot pain, young women

\section{INTRODUCTION}

Foot pain is very common and a large majority of individuals would have experienced it in his or her lifetime. It has been reported that approximately one in three people aged over 65 years have foot pain. ${ }^{(1,2)}$ However, the prevalence of foot pain in the younger population is less clear. A study by Spahn et al on 2,368 adolescents (average age 14.5 years) found the prevalence of foot pain to be only $14.0 \%{ }^{(3)}$ In a 2003 survey, the American Podiatric Medical Association ascertained that $62 \%$ of American women regularly wear footwear with heels over two inches in height, which are considered high-heeled. ${ }^{(4)}$ Most of the literature related to footwear and foot health is based on either Western societies or developed countries. To the best of our knowledge, despite obvious differences between Western and Asian countries with regard to social, cultural and ethnic compositions, as well as shoewearing habits, there is a lack of available infomation on footwear and foot health for Asian populations. Therefore, the objective of this study was to address this lack, as well as determine the prevalence of nontraumatic foot pain and its contributing factors in young working women aged between 21 and 40 years in an urban Asian setting.

\section{METHODS}

This was a population survey targeting women aged between
21 and 40 years who were working and residing in an urban community. Using convenience sampling, we invited the family members of young patients who were attending the orthopaedic and primary care outpatient clinics at University Malaya Medical Centre, Kuala Lumpur, Malaysia, to participate in this six-month study, which lasted from 1 January 2008 to 30 June 2008. Women from rural areas or who were not working were excluded from the study. Other exclusion criteria included any form of congenital foot deformity, a history of previous lower limb trauma that may have directly or indirectly altered the anatomy or bio-mechanics of the foot or ankle, and underlying chronic medical conditions such as inflammatory arthritis and diabetes mellitus.

In this study, 'foot pain' was defined as foot pain that occurred at least once a month and was not due to trauma in the past one year. Data on foot pain was collected using an investigator-directed questionnaire and during clinical inspection of the participant's foot. Information regarding the participant's demographics, education level, occupation, body weight (in $\mathrm{kg}$ ) and height (in $\mathrm{m}$ ) was also collected. Body mass index (BMI) was calculated based on World Health Organization's guideline, ${ }^{(5)}$ and participants were classified as either underweight $\left(\mathrm{BMI}<18.5 \mathrm{~kg} / \mathrm{m}^{2}\right)$, ideal weight (BMI 18.5-24.9 kg/m²), overweight (BMI 25.0-29.9 kg/m²) or obese $\left(\mathrm{BMI} \geq 30 \mathrm{~kg} / \mathrm{m}^{2}\right)$. Participants were also asked for

\footnotetext{
${ }^{1}$ Department of Orthopaedic Surgery, University of Malaya, Kuala Lumpur, ${ }^{2}$ Hospital Pakar Sultanah Fatimah Muar, Johor, Malaysia

Correspondence: Dr Chua Yeok Pin, Senior Lecturer and Orthopaedics Consultant, Department of Orthopaedic Surgery, Faculty of Medicine, University of Malaya, Lembah Pantai, 50603 Kuala Lumpur, Malaysia. yeokpin1@yahoo.com
} 
Table I. Demographics of participants $(n=400)$ and its relationship with nontraumatic foot pain.

\begin{tabular}{|c|c|c|c|c|c|}
\hline \multirow[t]{2}{*}{ Category } & \multicolumn{3}{|c|}{ No. of patients (\%) } & \multirow[t]{2}{*}{ p-value } & \multirow[t]{2}{*}{$\chi^{2}(\mathrm{df})$} \\
\hline & $\begin{array}{l}\text { Nontraumatic foot pain* } \\
\qquad(n=200)\end{array}$ & $\begin{array}{l}\text { No foot pain* } \\
(n=200)\end{array}$ & $\begin{array}{c}\text { Total } \\
(n=400)\end{array}$ & & \\
\hline Age group (yrs) & & & & 1.000 & $0.681(3)$ \\
\hline $21-25$ & $52(46.8)$ & $59(53.2)$ & $111(27.8)$ & & \\
\hline $26-30$ & $64(50.4)$ & $63(49.6)$ & $127(31.8)$ & & \\
\hline $31-35$ & $50(51.5)$ & $47(48.5)$ & $97(24.3)$ & & \\
\hline $36-40$ & $34(52.3)$ & $31(47.7)$ & $65(16.3)$ & & \\
\hline Ethnicity & & & & 0.093 & $4.742(2)$ \\
\hline Malay & $111(53.4)$ & $97(46.6)$ & $208(52.0)$ & & \\
\hline Chinese & $49(41.2)$ & $70(58.8)$ & $119(29.8)$ & & \\
\hline Indian & $35(52.2)$ & $32(47.8)$ & $67(16.8)$ & & \\
\hline Other & 5 (83.3) & $1(16.7)$ & $6(1.5)$ & & \\
\hline BMI category & & & & 0.985 & $1.337(3)$ \\
\hline Underweight $(\mathrm{BMI}<18.5$ kg/m²) & $27(43.5)$ & $35(56.5)$ & $62(15.5)$ & & \\
\hline Ideal weight (BMI 18.5-24.9 kg/m²) & $133(51.2)$ & $127(48.8)$ & $260(65.0)$ & & \\
\hline Overweight (BMI $25.0-29.9 \mathrm{~kg} / \mathrm{m}^{2}$ ) & $27(50.0)$ & $27(50.0)$ & $54(13.5)$ & & \\
\hline Obese $\left(\mathrm{BMI} \geq 30 \mathrm{~kg} / \mathrm{m}^{2}\right)$ & $13(54.2)$ & $11(45.8)$ & $24(6.0)$ & & \\
\hline
\end{tabular}

* Percentages were calculated as number of patients with nontraumatic foot pain (or no foot pain) in the category/total number of patients in that category $\times 100 \cdot \chi^{2}$ : chi-square; BMI: body mass index; df: degrees of freedom

information regarding the type of footwear worn to work, its comfort level and the duration of footwear use in a day. For those with a history of foot pain in the past one year, additional details noted included: (a) location of pain; (b) frequency of pain (per week); (c) severity of pain, graded according to the Numeric Intensity Scale (NIS); (d) participant's perception of whether the foot pain was caused by the footwear; and (e) whether formal medical attention was sought for the pain in the past one year. As the type of footwear worn is likely to have a greater impact on the occurrence of foot pain, footwear worn to work (which is typically worn for longer durations) was used to establish a possible association between the type of footwear worn and the prevalence of foot pain. The types of footwear worn to work by the women in our study were grouped based on the height of the shoes' heels - footwear with heels $>1$ inch were categorised as high-heeled, while those with heels $\leq 1$ inch were categorised as non-high-heeled.

Statistical analysis was performed using the Statistical Package for the Social Sciences for Windows version 16.0 (SPSS Inc, Chicago, IL, USA). Descriptive analysis of data involved the comparison of prevalence using chi-square test, with odds ratio (OR) and 95\% confidence intervals calculated. The difference between comfort and pain scores was tested using independent sample $t$-tests. The present study was approved by the institutional ethics committee.

\section{RESULTS}

A total of 400 urban working women were recruited for the study. The mean age of the women was $29.4 \pm 5.2$ years. The study group comprised 208 (52.0\%) Malays, 119 (29.8\%) Chinese, $67(16.8 \%)$ Indians and 6 (1.5\%) women of other ethnicities (Table I). The majority of the participants had received either a tertiary $(52.8 \%)$ or secondary $(45.8 \%)$ education, and most were employed in white-collar occupations. More than $60 \%$ of the women were professionals, or working as administrative or supportive staff.
Table II. Site of pain among working women with nontraumtic foot pain $(n=200)$.

\begin{tabular}{lc}
\hline Site of pain & No. (\%) \\
\hline Heel & $98(49.0)$ \\
Ball of foot/metatarsal heads & $50(25.0)$ \\
Medial arch & $24(12.0)$ \\
Toes & $20(10.0)$ \\
Lateral arch & $4(2.0)$ \\
Others (e.g. ankle joint and Achilles tendon) & $4(2.0)$ \\
\hline
\end{tabular}

Most $(n=260,65.0 \%$ ) of the participants in the present study had BMI within the optimal range, while 54 (13.5\%) were classified as overweight and $24(6.0 \%)$ were considered obese. When categorised according to the various age groups, we found no significant difference in the prevalence of recurrent nontraumatic foot pain among the women $(p=1.000)$. There was also no significant difference in its prevalence when the participants were subclassified according to BMI $(p=0.985)$ (Table I). A total of 200 (50.0\%) participants reported that they had recurrent nontraumatic foot pain. Of these 200 participants, 50 (25.0\%) experienced pain $<1$ day/week, while the pain lasted for 1-2 days/week for 83 (41.5\%) participants. For $42(21.0 \%)$ participants, the pain was present for 3-5 days/week, while in the remaining 25 (12.5\%) participants, pain was experienced for $>5$ days/week. Subjective assessments of the severity of foot pain using NIS provided a mean score of $4.89 \pm 1.78$ (range $2-10$ ). Overall, 97 (48.5\%) of the 200 participants with foot pain admitted to using some form of pain-relieving medication either orally or topically. Only $23(11.5 \%)$ of the 200 participants with pain sought formal medical treatment for the problem, with only $12(6.0 \%)$ requiring medical leave. The most frequent site of occurrence of foot pain was at the heel ( $n=98,49 \%)$. Other sites of foot pain included the metatarsal heads (i.e. ball of foot), medial arch, toes, lateral arch, and other sites such as the ankle joint and Achilles tendon (Table II). 
Table III. Comparison of the prevalence of nontraumatic foot pain, and perception of cause of foot pain among women in the study $(n=400)$ wearing high-heeled and non-high-heeled footwear.

\begin{tabular}{lcccc}
\hline Variable & \multicolumn{2}{c}{ No. of participants (\%) } & p-value $\left(\chi^{2}\right)$ & OR (95\% Cl) \\
\cline { 2 - 4 } & $\begin{array}{c}\text { High-heeled footwear } \\
(\mathbf{n}=\mathbf{2 1 3})\end{array}$ & $\begin{array}{c}\text { Non-high-heeled footwear } \\
(\mathbf{n}=\mathbf{1 8 7})\end{array}$ & & \\
\hline $\begin{array}{l}\text { Participants with nontraumatic } \\
\text { foot pain }(\mathbf{n}=\mathbf{2 0 0}) \\
\quad \begin{array}{l}\text { Participants who felt footwear } \\
\text { was the cause of foot pain }\end{array}\end{array}$ & $118 / 213(55.4)$ & $82 / 187(43.9)$ & $0.027(4.861)$ & $1.591(1.071-2.362)$ \\
\hline$\chi^{2}:$ chi-square; Cl: confidence interval; OR: odds ratio & $97 / 118(82.2)$ & $40 / 82(48.8)$ & $<0.001(23.522)$ & $4.850(2.556-9.201)$ \\
\hline
\end{tabular}

Footwear worn to work was worn for a significantly longer duration each day (7.36 hrs) than footwear for leisure activities (3.01 hrs). Among the participants with foot pain, 137 (68.5\%) felt that the foot pain was caused by the footwear they wore to work ( $p<0.001$; OR 4.850) (Table III). The remaining women were of the opinion that their foot pain was caused by reasons not associated with the footwear used ( $n=44$, $22.0 \%)$ or were unsure of its cause $(n=19,9.5 \%)$.

In our study group $(\mathrm{n}=400)$, high-heeled shoes ( $n=213,53.3 \%$ ) were the most popular footwear worn to work, followed by flat shoes $(n=112,28.0 \%)$, sandals $(n=39,9.8 \%)$, sports shoes $(n=25,6.3 \%)$, boots $(n=8,2.0 \%)$ and other types of shoes $(n=3,0.8 \%)$. We found that $55.4 \%$ of the participants who wore high-heeled footwear complained of foot pain compared to $43.9 \%$ of women who wore nonhigh-heeled footwear. There was a statistically significant difference between participants experiencing foot pain who wore high-heeled footwear and those who wore non-highheeled footwear ( $p=0.027$; OR 1.591).

\section{DISCUSSION}

Our study focused on young Asian working women from an urban environment. The racial distribution of patients (52.0\% Malay, $29.8 \%$ Chinese, $16.8 \%$ Indian, $1.5 \%$ other) in our study was similar to the findings of the National Population Census 2000 for women aged between 21 and 40 years in Kuala Lumpur and Selangor, Malaysia (52.5\% Malay, 31.6\% Chinese, $13.2 \%$ Indian, $2.7 \%$ other). ${ }^{(6)}$ In spite of differences in the social, cultural and footwear practices of people from different races, there was no statistically significant difference among participants of the three main ethnicities in our study with regard to the prevalence of foot pain $(p=0.093)$.

The American Orthopaedic Foot and Ankle Society shoe survey by Frey et $\mathrm{al}^{,{ }^{(7)}}$ which gathered information on 356 women aged between 20 and 60 years, reported that about $80 \%$ of women had substantial foot pain while wearing shoes. In contrast, only 50.0\% (200/400) of urban young working women in our study had recurrent nontraumatic foot pain. However, it is possible that the younger age of the participants in our study might have contributed to the lower number of women who reported foot pain, as it has been shown that the prevalence of foot pain increases with age. ${ }^{(8)}$ Nevertheless, notwithstanding the relatively young age of our cohort, the difference in the prevalence of foot pain among participants from the various age groups was not significant in our study $(p=1.000)$.

Hill et al reported that obesity, based on BMI, was associated with an increasing prevalence of foot pain. ${ }^{(8)}$ Similarly, Frey and Zamora found that in general, being overweight or obese significantly increased the chances of having tendonitis of the foot and ankle. ${ }^{(9)}$ The association between foot pain and obesity can partly be explained by the significant increase in force under the foot when walking for obese individuals. ${ }^{(10)} \mathrm{A}$ case-control study by Irving et al found that individuals with chronic heel pain were 2.9 times more likely to be obese. ${ }^{(11)}$ In our study, 54 (13.5\%) participants were classified as overweight and 24 (6.0\%) were considered obese. However, our study showed no statistically significant difference in the prevalence of foot pain between participants who were overweight or obese and those with normal BMI ( $p=0.985)$.

Even though recurrent nontraumatic foot pain affected up to $50 \%$ of the participants we surveyed, its impact was relatively low as the frequency of pain on a weekly basis was generally not high for most of the affected patients $-66.5 \%$ of the women had pain for two or less days per week. Further supporting this finding, only $11.5 \%$ of participants in our study sought formal medical attention for the pain, and only $6.0 \%$ of the 200 participants required medical leave due to foot pain in the past one year. We found the rate of disabling foot pain to be relatively low in our study when compared to the study by Garrow et al, which reported that $36 \%$ of their population with disabling foot pain received professional foot treatment in the six months prior to their survey. ${ }^{(12)}$ However, unlike the present study, patients with recent foot injury were included in the study by Garrow et al.

Just as there are many causes of foot pain, the area of involvement is also known to vary. The most common site of foot pain in our study was the heel (for $49.0 \%$ of affected women) followed by the ball of foot/metatarsal heads (25.0\%). This finding is contrary to other studies conducted on Western populations, which reported pain predominantly in the forefoot area. $^{(7,12)}$ This difference in findings may be attributed to differences in the cultural practices of Western and Asian populations. In most Asian countries, wearing shoes at home is a practice that is not only uncommon but also considered impolite. It is normal for most Asian women to walk on hard 
surfaces after working hours and during the weekends, when at home, without any shoes on. Although we did not specifically determine the underlying reason for heel pain in our patients, plantar fasciitis was most likely its main cause. Plantar fasciitis is thought to affect $10 \%$ of the general population and is considered the most common cause of heel pain. ${ }^{(13,14)}$ However, forefoot pain involving the toes and ball of foot (along the metatarsal heads) has a well-established association with ill-fitting footwear, especially in women wearing high-heeled shoes. ${ }^{(15-17)}$

Poorly fitted shoes have been identified as the principal cause of common foot disorders in women, ${ }^{(7,18)}$ although interestingly, the prevalence of foot problems is comparatively low in populations that do not wear shoes. ${ }^{(19,20)}$ Apart from giving rise to short-term problems such as recurrent foot pain, long-term morbidities such as progressive forefoot deformities and accelerated degenerative disorders have been attributed to ill-fitting footwear. Snow et al reported that women wearing shoes with elevated heels had a markedly increased pressure beneath the forefoot as compared to women not wearing shoes. ${ }^{(21)}$ High-heeled shoes have also been shown to shift the forefoot forward into the toe box, causing crowding of the toes and tightness of the heel cords. ${ }^{(18,22)}$ However, due to reasons such as societal pressure, dress codes and fashion trends, many women continue to prefer wearing high-heeled shoes that are narrower than their feet.

Footwear worn during work hours is likely to contribute more towards foot pain in young working women in an urban setting, as these are worn for a mean duration of more than seven hours a day. Accordingly, many (68.5\%) women in our study attributed their foot pain to footwear, with a significant proportion of patients (42.3\%) even having to remove footwear at work due to discomfort. Generally, we found that women wearing high-heeled shoes to work had a significantly higher association with foot pain than those wearing other types of footwear ( $p=0.027$; OR 1.591). Our results also indicated that a much higher proportion of participants in our study (53.3\%) wore high-heeled shoes to work than American women $(37 \%) .{ }^{(7)}$ A probable reason for this finding could be the higher proportion of professionals and white-collar workers among the women recruited for our study, a cohort for whom elements such as presentable image and formal office wear are of greater importance.

The present study was not without limitations. We were unable to investigate the underlying pathology of foot pain, as physical examinations of the foot other than gross inspection were not performed. Similarly, characteristics of the footwear worn by the participants, such as the shape of the toe box and its dimensions in relation to the width of the forefoot, were also not studied because most participants are likely to have more than one pair of shoes and any conclusions drawn from data analysis based on the pair of shoes worn to our centre would have been incomplete and misleading.
To summarise, the prevalence of recurrent nontraumatic foot pain in young Asian working women in our urban setting was around $50 \%$, with over half of the episodes involving high-heeled shoes. A high proportion of women (68.5\%) in our study attributed foot pain to their footwear and slightly more than half of the cohort (53.3\%) wore high-heeled shoes to work. Our results underscore the importance of concerted efforts toward making women more aware of the adverse effects of wearing ill-fitting footwear such as high-heeled shoes that are too narrow. Increased awareness in women on proper footwear may help to modify selection patterns for shoes worn, especially those worn during work hours, thus reducing the occurrence of various foot problems associated with highheeled shoes, including recurrent foot pain.

\section{REFERENCES}

1. Dunn JE, Link CL, Felson DT, et al. Prevalence of foot and ankle conditions in a multiethnic community sample of older adults. Am J Epidemiol 2004; 159:491-8.

2. Black JR, Hale WE. Prevalence of foot complaints in the elderly. J Am Podiatr Med Assoc 1987; 77:308-11.

3. Spahn G, Schiele R, Hell AK, et al. [The prevalence of pain and deformities in the feet of adolescents. Results of a cross-sectional study]. Z Orthop Ihre Grenzgeb 2004; 142:389-96. German

4. American Podiatric Medical Association. High Heel Survey 2003 (online). Available at: www.apma.org/s_apma/ doc.asp?CID = 385\&DID = 1711 . Accessed November 23, 2006.

5. World Health Organization. Obesity: preventing and managing the global epidemic. Geneva: World Health Organization, 1997.

6. Department of Statistics Malaysia. Population and Housing Census of Malaysia 2010. National Population Demographics Census Year 2000 for female aged 21 to 40 in Kuala Lumpur and Selangor. Available at: www.statistics.gov.my/mycensus2010. Accessed July 23, 2011.

7. Frey C, Thompson F, Smith J, Sanders M, Horstman H. American Orthopaedic Foot and Ankle Society women's shoe survey. Foot Ankle 1993; 14:78-81.

8. Hill CL, Gill TK, Menz HB, Taylor AW. Prevalence and correlates of foot pain in a population-based study: the North West Adelaide health study. J Foot Ankle Res 2008; 1:2.

9. Frey C, Zamora J. The effect of obesity on the orthopaedic foot and ankle pathlogy. Foot Ankle Int 2007; 28:996-9.

10. Birtane $M$, Tuna $H$. The evaluation of plantar pressure distribution in obese and non-obese adults. Clin Biomech (Bristol, Avon) 2004; 19:1055-9.

11. Irving DB, Cook JL, Young MA, Menz HB. Obesity and pronated foot type may increase the risk of chronic plantar heel pain: a matched case-control study. BMC Musculoskelet Disord 2007; 8:41.

12. Garrow AP, Silman AJ, Macfarlane GJ. The Cheshire Foot Pain and Disability Survey: a population survey assessing prevalence and associations. Pain 2004; 110:378-84.

13. Riddle DL, Pulisic M, Pidcoe P, Johnson RE. Risk factors for Plantar fasciitis: a matched case-control study. J Bone Joint Surg Am 2003; 85-A:872-7.

14. Neufeld SK, Cerrato R. Plantar fasciitis: evaluation and treatment. J Am Acad Orthop Surg 2008; 16:338-46.

15. Menz HB, Morris ME. Footwear characteristics and foot problems in older people. Gerontology 2005; 51:346-51.

16. Frey C, Thompson F, Smith J. Update on women's footwear. Foot Ankle Int 1995; 16:328-31.

17. Broch NL, Wyller T, Steen H. Effects of heel height and shoe shape on the compressive load between foot and base: a graphic analysis of principle. J Am Podiatr Med Assoc 2004; 94:461-9.

18. Coughlin MJ, Thompson FM. The high price of high-fashion footwear. Instr Course Lect 1995; 44:371-7.

19. Sim-Fook L, Hodgson AR. A comparison of foot forms among non-shoe and shoe-wearing Chinese population. J Bone Joint Surg Am 1958; 40-A:1058-62.

20. Hoffman P. Conclusions drawn from a comparative study of the feet of barefooted and shoe-wearing peoples. Am J Orthop Surg 1905; s2-3:105-36.

21. Snow RE, Williams KR, Holmes GB Jr. The effects on wearing high heeled shoes on pedal pressure in women. Foot Ankle 1992; 13:85-92.

22. Frey C. Foot health and shoewear for women. Clin Orthop Relat Res 2000; 372: 32-44. 